Int. J. Electrochem. Sci., 13 (2018) 10669 - 10678

International Journal of

ELECTROCHEMICAL

SCIENCE

wWw.electrochemsci.org

Short Communication

\title{
Corrosion Behavior of X65 and X80 Pipeline Steels under AC Interference Condition in High pH Solution
}

\author{
Min Zhu*, Yongfeng Yuan, Simin Yin, Shaoyi Guo
}

School of Mechanical Engineering \& Automation, Zhejiang Sci-Tech University, Hangzhou 310018, PR China

*E-mail: zmii666@126.com

doi: $10.20964 / 2018.11 .54$

Received: 27 July 2018 / Accepted: 20 August 2018 / Published: 1 October 2018

The corrosion behavior of X65 and X80 pipeline steels under AC interference in high pH solution was investigated by potentiodynamic polarization curve, open circuit potential, Mott-Schottky curve and immersion test. The results show that AC could significantly reduce the passivity of the steels, interfere with the formation of passive film, increase the instability of passive film formed on the steel, and AC with high $i_{A C}$ generates a more damage to the film. The film on X65 steel has a worse stability, with a larger corrosion rate. Under AC interference, X65 steel has a worse corrosion resistance, with a more severe localized corrosion. While X80 steel exhibits a better corrosion resistance, with a slighter corrosion status. The microstructure consisting of ferrite and pearlite is more susceptibility to AC corrosion.

Keywords: AC interference; passive film; stability; corrosion resistance; microstructure

\section{$\underline{\text { FULL TEXT }}$}

(C) 2018 The Authors. Published by ESG (www.electrochemsci.org). This article is an open access article distributed under the terms and conditions of the Creative Commons Attribution license (http://creativecommons.org/licenses/by/4.0/). 